\title{
Desain Model Basisdata Monitoring Perawatan dan Perkembangan Kesehatan Anak Paud Melalui Metode Holistik Integratif
}

\author{
Erly Krisnanik $^{1}$, Tri Rahayu ${ }^{2}$, Duma Lumban Tobing ${ }^{3}$ \\ Fakultas Ilmu Komputer ${ }^{1,2}$, Fakultas Ilmu Kesehatan ${ }^{3}$ \\ Universitas Pembangunan Nasional Veteran Jakarta \\ 1erlykrisnanik@upnvj.ac.id, ${ }^{2}$ ayu_sml@yahoo.com, ${ }^{3}$ duma.yosephine76@gmail.com \\ Jl. RS. Fatmawati, Pondok Labu, Jakarta Selatan, DKI Jakarta, 12450, Indonesia
}

\begin{abstract}
Abstrak. Kementerian Riset, Teknologi, dan Pendidikan Tinggi Republik Indonesia (Kemenristekdikti RI) telah mencanangkan program untuk kesehatan masyarakat yang dituangkan kedalam Rencana Induk Riset Nasional (RIRN) tahun 2017-2045. Kualitas hidup sumber daya manusia (SDM) merupakan pondasi utama bagi pembangunan, hal ini disebkan karena kualitas SDM sangat menentukan kemajuan suatu bangsa. Kualitas SDM antara lain dicerminkan oleh derajat kesehatan, tingkat intelegensia, kematangan emosional dan spiritual yang ditentukan oleh kualitas anak sejak janin dalam kandungan hingga anak berusia 6 tahun. Tujuan dari penelitian ini adalah untuk meningkatkan kualitas hidup anak paud melalui desain model basisdata monitoring kesehatan anak paud melalui metode pendekatan holistic integratif yang terdiri dari beberapa aspek: 1) Pemenuhan gizi bagi anak paud, 2) Penjadwalan imunisasi dan 3) Perawatan pertumbuhan anak paud. sedangkan manfaat dari penelitian ini adalah memberikan kemudahan pada pengelola Paud untuk memonitoring anak didiknya dalam pemeliharaan kesehatan mulai dari kebutuhan gizi, pemberian imunisasi yang teratur dan pertumbungan/ perkembangan anak Paud Metodologi penelitian yang digunakan dalam pengembangan desain model basisdata menggunakan Basisdata Life Cycle (DBLC).
\end{abstract}

Keywords: Anak Paud, Holistik Integratif, Gizi, Imunisasi dan Perkembangan_anak_paud

\section{PENDAHULUAN}

Kementerian Riset, Teknologi, dan Pendidikan Tinggi Republik Indonesia (Kemenristekdikti RI) telah mencanangkan program untuk kesehatan masyarakat yang dituangkan kedalam Rencana Induk Riset Nasional (RIRN) tahun 2017-2045. Berdasarkan hal tersebut peneliti ingin membantu pemerintah dalam mewujudkan masyarakat yang memiliki kualitas hidup yang baik terutama dalam hal kesehatan sehingga mengurangi jumlah angka kematian terutama di kota Serang banten yang Jumlah Kematian Balita pada tahun 2015 sebesar 8 kasus dari 13.353 kelahiran hidup. Bila di hitung dengan formula Angka Kematian Balita per 1000 kelahiran hidup, Angka Kematian Balita di Kota Serang adalah sebesar 0.7/1000 kelahiran hidup. (Dinas kesehatan, 2015). Kualitas manusia dicerminkan oleh tingkat kesehatan, intelegensia, kematangan emosional dan spiritual yang dapat dilihat dari kualitas perkembangan anak sejak janin dalam kandungan hingga anak berusia 6 tahun yang dikenal dengan istilah "Golden Egg". Menurut DR Sidibyo pada periode tersebut seorang anak membutuhkan asupan gizi seimbang, kesehatan, pedidikan dan pengasuhan yang baik dan benar agar anak dapat tumbuh kembang secara optimal, Oleh sebab itu dalam menciptakan manusia yang bermutu, perlu dilakukan sejak dini dengan memenuhi kebutuhan dasar anak. Pemenuhan kebutuhan dasar tersebut melalui program yang terintegrasi meliputi pemeliharaan kesehatan, pemenuhan gizi, pendidikan, pengasuhan, dan perlindungan guna memenuhi semua kebutuhan dasar anak. (DR. Sudibyo Alimoeso, 2013). Menurut Notoatmodjo 2016, Perilaku kesehatan (healthy behavior) dapat diartikan sebagai tanggapan seseorang terhadap stimulus atau objek yang berkaitan dengan kesehatan, penyakit, dan faktor-faktor yang dapat memengaruhi kesehatan seperti lingkungan, makanan, minuman, dan pelayanan kesehatan. Perilaku kesehatan merupakan semua aktivitas atau kegiatan seseorang, baik yang dapat diamati (observable) maupun yang tidak dapat diamati (unobservable), yang berkaitan dengan pemeliharaan dan peningkatan kesehatan. Pemeliharaan kesehatan ini mencakup mencegah atau melindungi diri dari penyakit dan masalah kesehatan lain, meningkatkan kesehatan, dan mencari penyembuhan apabila sakit atau terkena masalah kesehatan. (Apriliana Kuntoro Astuti, 2016).

Sedangkan menurut pakar penyelenggaran pendidikan anak usia dini secara holistik integratif penting untuk di kaji karena akan memunculkan komunikasi yang baik antara orang tua dengan sekolah, orang tua satu 
dengan orang tua yang lainnya, dan dapat menambah pengetahuan dan keterampilan orang tua dalam mengasuh dan mendidik anak (Linawati Zulfa Indra Laila, 2013). Penyelenggaran holistik integratif yang diterapkan di Paud dengan bina keluarga balita dan Posyandu juga sangat efektif dibandingkan dengan pelayanan yang hanya dilakukan oleh posyandu atau bina keluarga balita secara mandiri. Hal ini dapat dilihat dari ketertarikan orang tua untuk datang ke Pos Paud yang terintegrasi dengan posyandu dan bina keluarga balita untuk mengetahui tentang pelayanan anak usia dini (S, Zahraini, \& Sabarini, 2013).

Menurut pakar pembelajaran holistik-integratif berasumsi bahwa pikiran secara alami (naluriah) senantiasa mencari arti setiap hal dalam konteksnya, yaitu lingkungan tempat ia berada. Sejalan dengan hal ini, Karweit menuturkan bahwa dalam pembelajaran holistik - integratif, pembelajaran didesain agar anak dapat memecahkan persoalan melalui kegiatan yang merefleksikan kejadian sebenarnya dalam kehidupan (Suyanto, 2015:151).

Berdasarkan hal tersebut maka perlu adanya pengolahan data terhadap perkembangan dan pertumbuhan anak PAUD secara holistic integrative mulai dari pemenuhan gizi seimbang, Perawatan pertumbuhan anak paud, dan penjadwalan imunisasi. Dengan dibangunnya basisdata maka dapat digunakan sebagai media untuk penyimpanan data pertumbuhan dan perkembangan anak PAUD sehingga memudahkan pengelola PAUD untuk melakukan monitoring

\section{METODOLOGI PENELITIAN}

Metode yang digunakan untuk monitoring kesehatan anak paud menggunakan pendekatan holistik integratif yang meliputi beberapa aspek yaitu: 1) Pemenuhan gizi bagi anak paud, 2) Penjadwalan imunisasi dan 3) Perawatan pertumbuhan anak paud. Sedangkan metodelogi penelitian yang digunakan dalam desain model basisdata monitoring kesehatan anak paud menggunakan Basisdata Life Cycle (DBLC) yang terdiri dari beberapa tahap yaitu:

a. Menyusun perencanaan basisdata yang dibuat untuk monitoring kesehatan anak paud.

b. Merumuskan definisi sistem dari basisdata yang dibangun.

c. Melakukan analisis dan pengumpulan kebutuhan/persyaratan dalam membangun basisdata.

d. Merancang basisdata meliputi: 1) konseptual model basisdata, 2) perancangan logic basisdata dan 3) perancangan fisik basisdata

e. Perancangan aplikasi basisdata melalui desain user interface

f. Implementasi rancangan basisdata

g. Pengujian sistem basis data, pada tahap ini dilakukan uji coba untuk aplikasi basisdata yang dirancang.

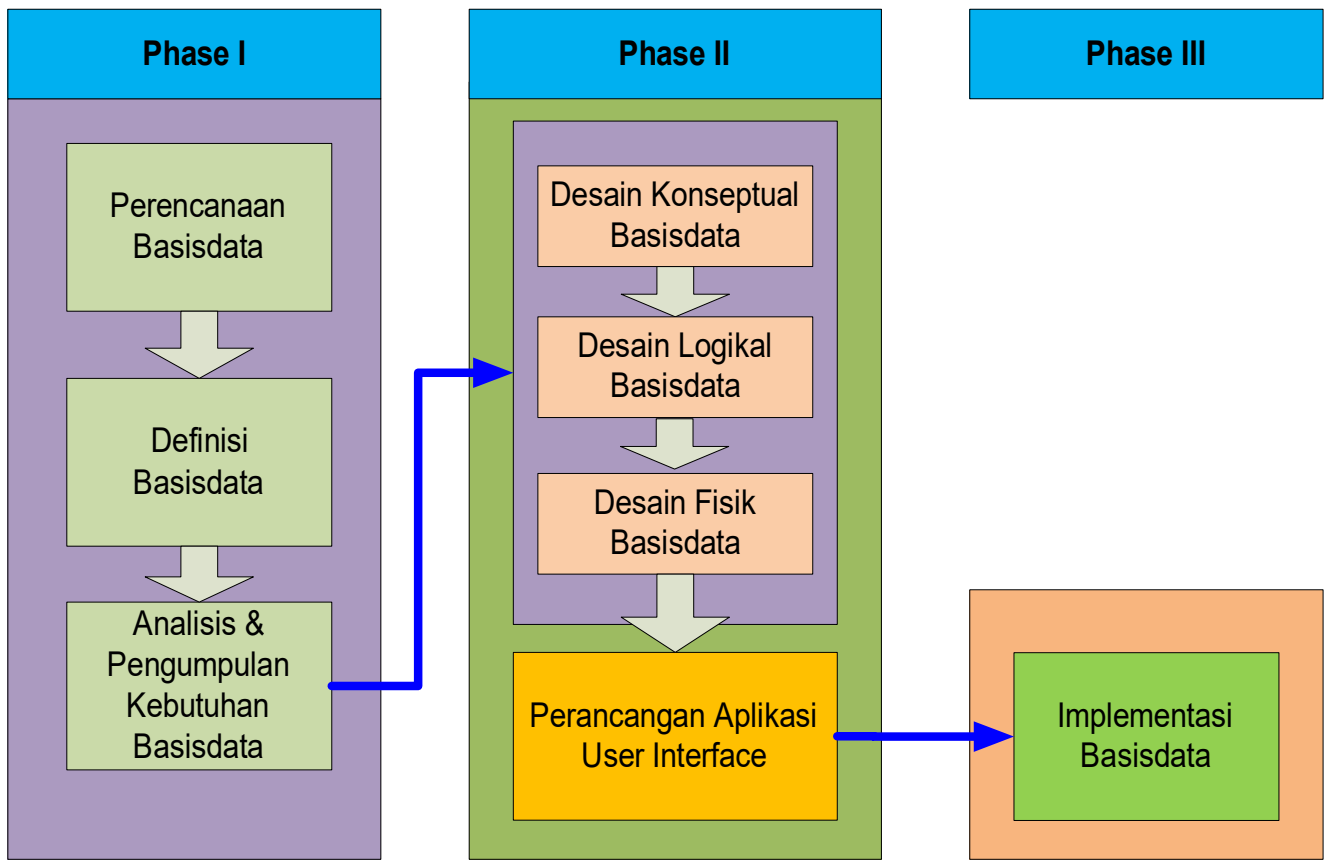

Gambar 1. Tahapan Penelitian menggunakan DBLC 
Tujuan dari penelitian ini adalah untuk meningkatkan kualitas hidup anak paud melalui desain model basisdata monitoring kesehatan melalui metode pendekatan holistic integratif agar dapat memantau pengembangan anak usia dini yang meliputi: 1) kebutuhan Pemenuhan gizi bagi anak paud, 2) Penjadwalan imunisasi dan 3) Perawatan perkembangan anak paud. Sedangkan manfaat dari penelitian ini adalah memberikan kemudahan pada pengelola Paud untuk memonitoring perkembangan dan pertubuhan anak didiknya.

Kontribusi yang telah peneliti laksanakan dari hasil penelitian ini berupa desain model basisdata monitoring kesehatan anak PAUD pada Kuntum Mekar dan PAUD Assibyan sehingga mereka dapat memantau perkembangan anak didiknya menjadi anak yang sehat, cerdas dan kuat. Selain itu kontribusi terhadap keilmuan adalah berupa optimalisasi penggunaan basisdata yang dapat diandalkan sebagai pengolahan data dengan rancangan basisdata yang memiliki relasi dengan derajat cardinality one to one, one to many/many to one serta many to many.

\section{HASIL DAN PEMBAHASAN}

\subsection{Perancangan Model Basisdata Monitoring Perkembangan Dan Kesehatan Anak Paud}

\subsubsection{Perencanaan Basisdata Monitoring Perkembangan dan Kesehatan Anak Paud}

Peneliti telah melakukan kajian untuk menyusun perencanaan dalam membangun basisdata monitoring kesehatan bagi anak paud Kuntum Mekar dan paud Assibyan yang berada di daerah Serang Banten. Desain model yang dirancang untuk monitoring kesehatan dan perkembangan anak paud menggunakan pendekatan holistic integratif yang meliputi: 1) kebutuhan Pemenuhan gizi bagi anak paud, 2) Penjadwalan imunisasi dan 3) Perawatan anak paud. Berdasarkan hal tersebut maka terdapat 3 model basisdata untuk menampung aktifitas yang dilakukan oleh manajemen paud terhadap anak didiknya terdiri dari:

a. Basisdata kebutuhan gizi anak paud (terdiri dari tabel anak paud, tabel perkembangan gizi anak paud, menu sehat anak paud)

b. Basisdata Penjadwalan imunisasi anak paud (terdiri dari tabel anak paud, tabel jadwal pemberian imunisasi, tabel jenis imunisai dan tabel daftar ulang imunisasi)

c. Basisdata Perawatan anak paud (terdiri dari tabel anak paud, tabel pertumbuhan anak paud, tabel perawatan gigi, dan tabel pemberian vitamin)

Hubungan antara ketiga basisdata tersenbut terhadap montoring perkembangan dan kesehatan anak paud dengan pendekatan holistic integrative dapat dilihat pada gambar 2.

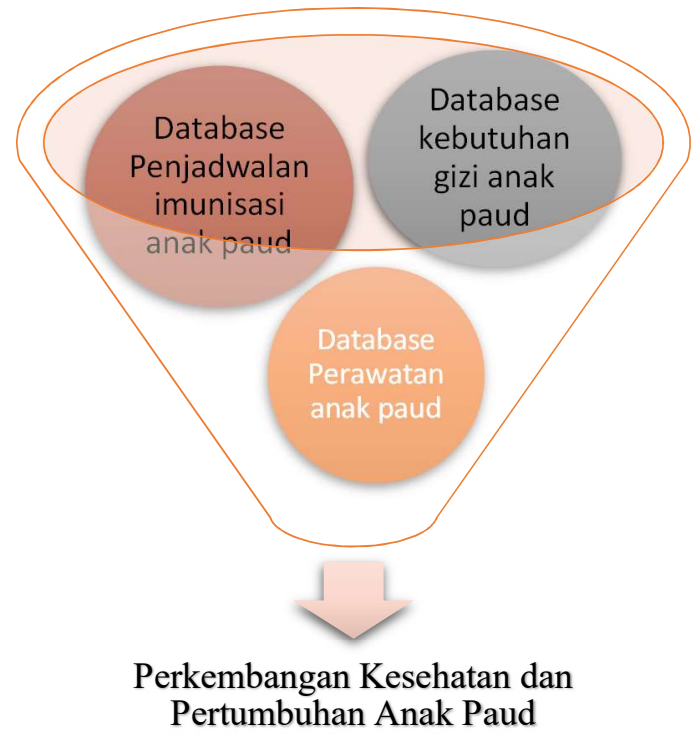

Gambar 2 Hubungan antara 3 model basisdata 


\subsubsection{Definisi Basisdata Monitoring Perawatan Perkembangan dan Kesehatan Anak Paud}

Batasan sistem dalam perancangan desain model basisdata Monitoring Perkembangan dan Kesehatan Anak Paud adalah mencangkup aktifitas kegiatan anak paud selama mengikuti pendidikan di sekolah Paud dengan kontroling dari pihak penyelenggara Paud bekerjasama dengan orang tua wali murid. Adapun peran dari actor yang terkait dengan model sistem dapat dilihat pada tabel 1 .

Tabel 1 Tabel user definisi berdasarkan kebutuhan

\begin{tabular}{l|l|ll}
\hline No. & Aktor & & \multicolumn{1}{c}{ Aktifitas } \\
\hline 1. & Guru Paud & a. & Membuat data master anak paud \\
& & b. Membuat daftar menu sehat anak paud \\
& & c. Membuat monitoring perkembangan gizi anak paud \\
& & d. Membuat jadwal imunisasi \\
& & e. Membuat monitoring perekaman data imunisasi anak paud \\
& & f. Membuat jadwal perawatan kesehatan anak paud \\
& & g. Membuat monitoring perekaman data perkembangan kesehatan \\
& & h. Membuat jadwal pemberian vitamin bagi anak paud \\
\hline 2. & Anak Paud & a. Mengikuti jadwal makan menu sehat \\
& & b. Mengikuti jadwal imunisasi \\
& & c. Mengikuti jadwal perawatan kesehatan \\
& & d. Mengikuti jadwal pemberian vitamin \\
\hline 3. & Orang Tua & a. Memantau perkembangan gizi anaknya \\
& & b. Memantau pemberian imunisasi \\
& & c. Memantau pemberian vitamin \\
& & d. Memantau kegiatan perawatan kesehatan \\
& & e. Memantau monitoring hasil perkembangan dan kesehatan \\
\hline
\end{tabular}

\subsubsection{Analisis dan pengumpulan kebutuhan Basisdata}

Pada tahap ini telah dilakukan analisis kebutuhan data berdasarkan observasi langsung dan wawancara dengan pihak paud Kuntum Mekar dan paud Assibyan serta orang tua dari anak paud. Hasil dari analisis kebutuhan tersebut adalah:

a. Analisis Kebutuhan Informasi. Pengelola Paud Kuntum Mekar dan Paud Assibyan mengalami kesulitan dalam monitoring terhadap aktifitas yang telah mereka lakukan dan kerjakan selama periode waktu tertentu. Hal ini terjadi karena setiap kegiatan yang telah mereka kerjakan tidak terdokumentasi dengan baik sehingga pada saat data tersebut dibutuhkan pihak manajemen Paud mengalami kesulitan dalam menyusun laporan. Berdasarkan permasalahan tersebut maka perlu adanya pengolahan data menggunakan basisdata sehingga aktifitas yang telah mereka kerjakan dapat disimpan dan digunakan kembali sebagai bahan kajia dan pelaporan.

b. Analisis Kebutuhan Penyimpanan Data. Data tentang perkembangan anak paud sering hilang dan rusak karena dimakan rayap atau masa dari media penyimpanan yang tidak baik. Berdasarkan hal tersebut maka peneliti memberikan saran kepada pihak pengelola paud untuk menyediakan aplikasi basisdata sebagai media untuk penyimpanan data dan pengolahan data anak-anak paud.

c. Analisis Kebutuhan Teknologi. Selama ini pihak paud Kuntum Mekar dan Paud Assibyan belum menggunakan teknologi sebagai media untuk pengolahan data. Hal ini mengakibatkan pihak manajemen pengelola paud mengalami kesulitan pada saat membuat laporan perawatan perkembangan dan pertumbuhan kesehatan anak paud. Oleh karena itu penggunaan teknologi yang tepat merupakan salah satu solusi untuk memberikan layanan kepada orang tua dan pengelola paud sehingga perkembangan dan pertumbuhan anak paud dapat dilakukan secara optimal.

3.2 Perancangan basisdata dan user interface untuk desain model basisdata monitoring perkembangan dan kesehatan anak paud

\subsubsection{Perancangan Basisdata}

a. Perancangan Konseptual Basisdata

Pada penelitian ini telah menghasilkan 12 tabel yang saling berelasi terdiri dari 5 tabel master dan 6 tabel transaksi, 2 tabel antara. Adapun penamaan tabel tersebut adalah sebagai berikut: 
1) Tabel Master: tb_Anak_Paud, tb_imunisasi, tb_vitamin, tb_menu_sehat, tb jenis monitoring.

2) Tabel Transaksi: tb_perkembangan_AUD, tb_monitoring_imunisasi, tb_detail_jadwal, tb_perkembangan_gz, tb_perawatan_gigi

3) Tabel Antara: tb_monitoring_AUD, tb_jadwal

b. Perancangan Logik Basisdata

Perancangan logic basisdata untuk monitoring kesehatan anak PAUD dapat dilihat pada tabel gambar 3 yang telah menggambarkan beberapa tabel menjadi

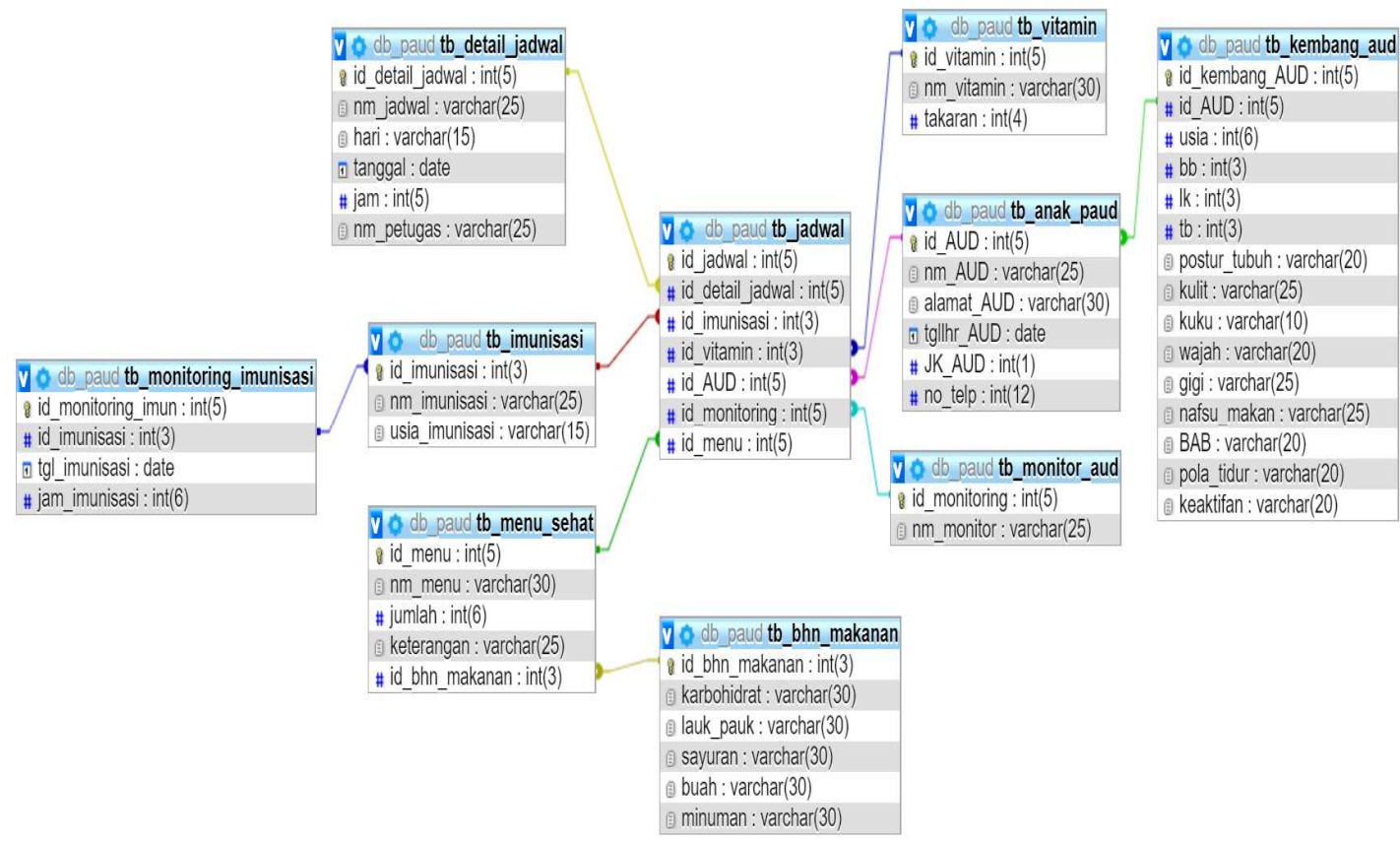

Gambar 3 Hubungan antar tabel monitoring kesehatan anak usia dini berbasis holistic integrative

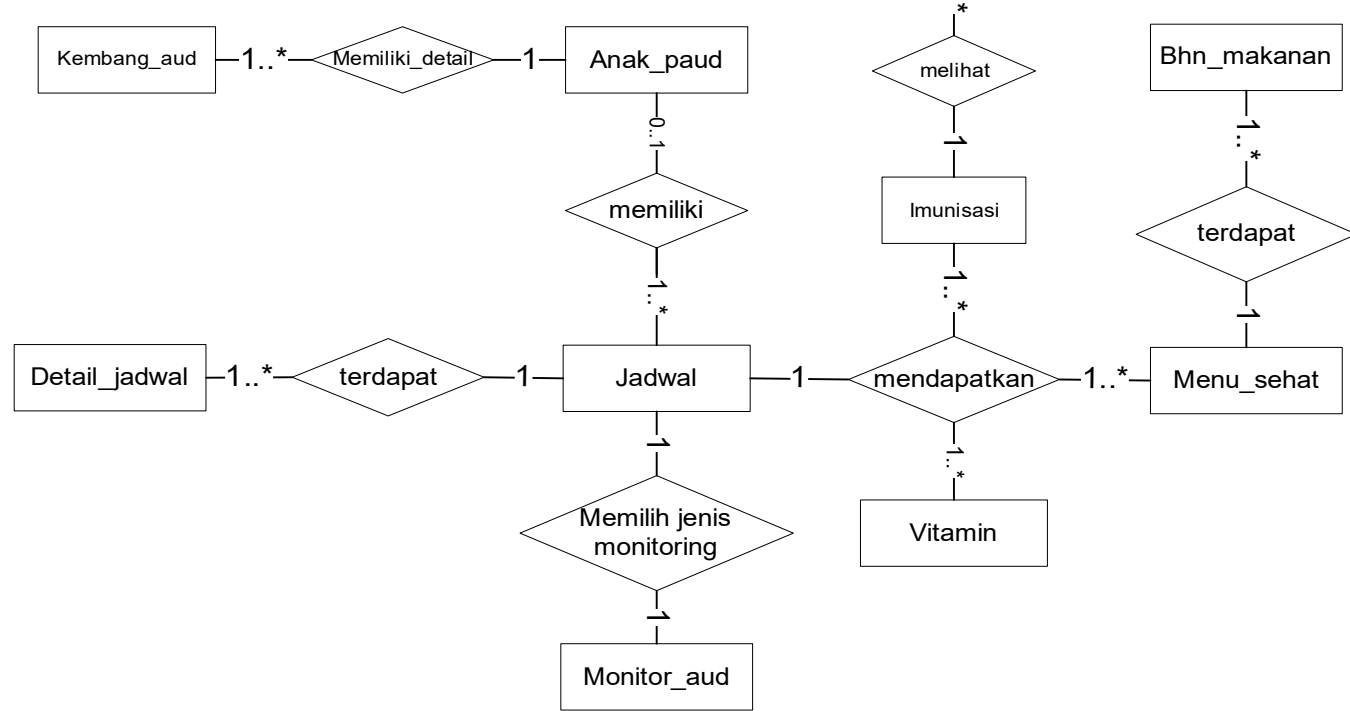

Gambar 4 ER Model monitoring kesehatan anak usia dini berbasis holistic integrative 
c. Perancangan Fisik Basisdata

1) Struktur tabel: tb anak_paud

\begin{tabular}{|l|l|l|l|}
\hline \multicolumn{1}{|c|}{ Column } & \multicolumn{1}{c|}{ Type } & \multicolumn{1}{c|}{ NNull } & \multicolumn{1}{c|}{ Default } \\
\hline id_AUD & int(5) & No & PK \\
\hline nm_AUD & $\operatorname{varchar}(25)$ & No & \\
\hline alamat_AUD & $\operatorname{varchar}(30)$ & No & \\
\hline tgllhr_AUD & date & No & \\
\hline JK_AUD & int(1) & No & \\
\hline no_telp & $\operatorname{int}(12)$ & No & \\
\hline
\end{tabular}

2) Struktur tabel: tb_detail_jadwal

\begin{tabular}{|l|l|l|l|}
\hline \multicolumn{1}{|c|}{ Column } & \multicolumn{1}{c|}{ Type } & \multicolumn{1}{c|}{ Null } & Default \\
\hline id_detail_jadwal & $\operatorname{int}(5)$ & No & PK \\
\hline nm_jadwal & $\operatorname{varchar}(25)$ & No & \\
\hline hari & $\operatorname{varchar}(15)$ & No & \\
\hline tanggal & date & No & \\
\hline jam & int(5) & No & \\
\hline nm_petugas & $\operatorname{varchar}(25)$ & No & \\
\hline
\end{tabular}

3) Struktur tabel: tb_imunisasi

\begin{tabular}{|l|c|c|c|}
\hline \multicolumn{1}{|c|}{ Column } & Type & Null & Default \\
\hline id_imunisasi & $\operatorname{int}(3)$ & No & PK \\
\hline nm_imunisasi & $\operatorname{varchar}(25)$ & No & \\
\hline usia_imunisasi & varchar(15) & No & \\
\hline
\end{tabular}

4) Struktur tabel: tb_bhn makanan

\begin{tabular}{|l|l|l|l|}
\hline Column & Type & Null & Default \\
\hline id_bhn_makanan & $\operatorname{int}(5)$ & No & PK \\
\hline karbohidrat & varchar(30) & No & \\
\hline lauk_pauk & varchar(30) & No & \\
\hline sayuran & varchar(30) & No & \\
\hline buah & varchar(30) & No & \\
\hline minuman & varchar(30) & No & \\
\hline
\end{tabular}

5) Struktur tabel: tb_kembang_aud

\begin{tabular}{|l|l|l|l|}
\hline Column & Type & Null & Default \\
\hline id_kembang_AUD & $\operatorname{int}(5)$ & No & PK \\
\hline usia & $\operatorname{int}(6)$ & No & \\
\hline bb & $\operatorname{int}(3)$ & No & \\
\hline lk & $\operatorname{int}(3)$ & No & \\
\hline tb & $\operatorname{int}(3)$ & No & \\
\hline postur_tubuh & $\operatorname{varchar}(20)$ & No & \\
\hline kulit & $\operatorname{varchar}(25)$ & No & \\
\hline kuku & $\operatorname{varchar}(10)$ & No & \\
\hline wajah & $\operatorname{varchar}(20)$ & No & \\
\hline gigi & $\operatorname{varchar}(25)$ & No & \\
\hline nafsu_makan & $\operatorname{varchar}(25)$ & No & \\
\hline BAB & $\operatorname{varchar}(20)$ & No & \\
\hline pola_tidur & $\operatorname{varchar}(20)$ & No & \\
\hline keaktifan & $\operatorname{varchar}(20)$ & No & \\
\hline
\end{tabular}


6) Struktur tabel: tb_menu sehat

\begin{tabular}{|l|l|l|l|}
\hline Column & Type & Null & Default \\
\hline id_menu & $\operatorname{int}(5)$ & No & PK \\
\hline nm_menu & varchar(30) & No & \\
\hline jumlah & varchar(6) & No & \\
\hline keterangan & varchar(20) & No & \\
\hline id_bhn_makanan & $\operatorname{int}(5)$ & No & \\
\hline
\end{tabular}

7) Struktur tabel: tb monitoring imunisasi

\begin{tabular}{|l|l|l|l|}
\hline Column & Type & Null & Default \\
\hline id_monitoring_imun & $\operatorname{int}(5)$ & No & PK \\
\hline id_imunisasi & $\operatorname{int}(3)$ & No & FK \\
\hline tgl_imunisasi & date & No & \\
\hline jam_imunisasi & $\operatorname{int}(6)$ & No & \\
\hline
\end{tabular}

8) Struktur tabel: tb_vitamin

\begin{tabular}{|l|l|l|l|}
\hline \multicolumn{1}{|c|}{ Column } & \multicolumn{1}{c|}{ Type } & \multicolumn{1}{c|}{ Null } & Default \\
\hline id_vitamin & $\operatorname{int}(5)$ & No & PK \\
\hline nm_vitamin & $\operatorname{varchar}(30)$ & No & \\
\hline takaran & $\operatorname{int}(4)$ & No & \\
\hline
\end{tabular}

9) Struktur tabel: table tb_jadwal

\begin{tabular}{|l|c|c|c|}
\hline Column & Type & Null & Default \\
\hline id_jadwal & $\operatorname{int}(5)$ & No & PK \\
\hline id_detail_jadwal & $\operatorname{int}(5)$ & No & FK \\
\hline id_imunisasi & $\operatorname{int}(3)$ & No & FK \\
\hline id_vitamin & $\operatorname{int}(3)$ & No & FK \\
\hline id_AUD & $\operatorname{int}(5)$ & No & FK \\
\hline id_menu & $\operatorname{int}(5)$ & No & FK \\
\hline id_monitor & $\operatorname{int}(5)$ & No & FK \\
\hline
\end{tabular}

10) Struktur tabel: tb_monitor_aud

\begin{tabular}{|l|l|l|l|}
\hline Column & Type & Null & Default \\
\hline id_monitoring & $\operatorname{int}(5)$ & No & FK \\
\hline nm_monitor & $\operatorname{varchar}(25)$ & No & FK \\
\hline
\end{tabular}

\subsubsection{Perancangan Aplikasi User Interface}

Perncangan user interface sangat di butuhkan karena untuk memudahkan pengguna sistem melakukan pengelolaan terhadap perubahan data anak PAUD mulai dari perekaman data anak PAUD, kesehatan anak PAUD dan kontroling pemberian imunisasi bagi anak PAUD. Perancangan user interface dapat dilihat pada gambar berikut ini. 


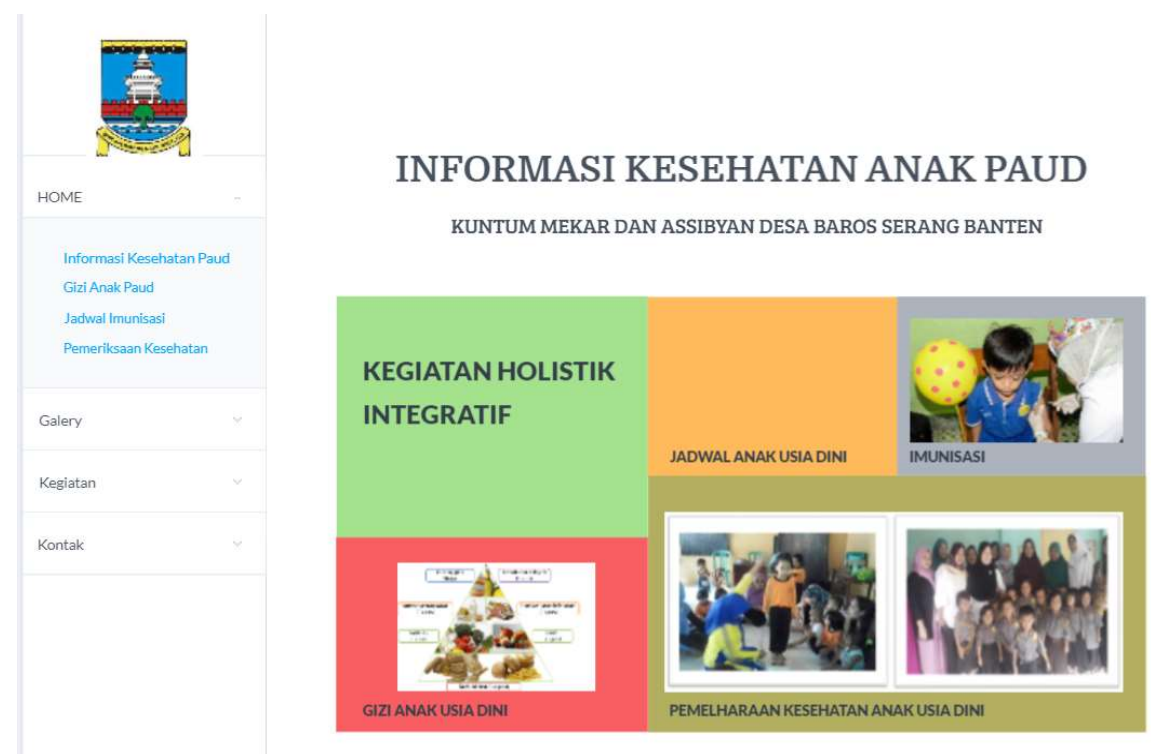

Gambar 4 Rancangan dashboard untuk pengguna sistem informasi kesehatan Anak PAUD

Pada gambar 5 terdapat modul sistem yang dirancang untuk memonitoring kesehatan anak PAUD dengan pendekatan Holistik Integratif mulai dari informasi kesehatan anak PAUD, pertumbuhan Gizi anak PAUD, jadwal imunisasi anak PAUD, dan pemeriksaan kesehatan anak PAUD. selain itu terdapat aktifitas kegiatan yang telah dilakukan oleh PAUD Kuntum Mekar dan PAUD Assibyan serta Galery foto kegiatan yang telah dilaksanakan.

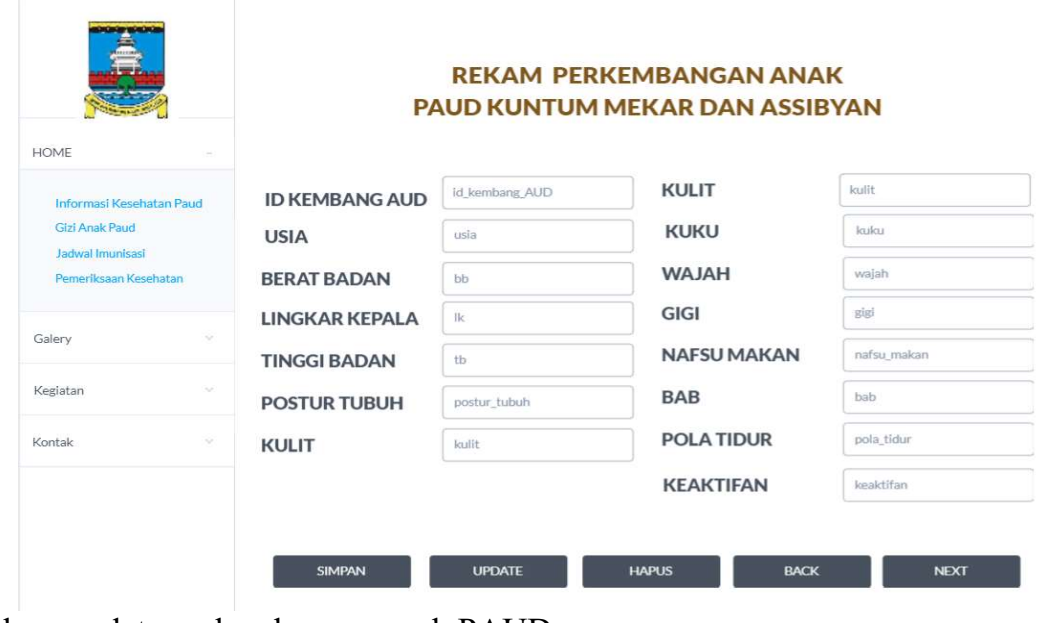

Gambar 5 Perekaman data perkembangan anak PAUD

Pada gambar 6 merupakan rancangan untuk rekam perkembangan anak PAUD untuk dapat melihat pertumbuhannya apakah sudah sesuai dengan standar perkembangan berdasarkan usia, berat badan, tinggi badan dan lingkar kepala.

\section{KESIMPULAN DAN SARAN}

\subsection{KESIMPULAN}

Berdasarkan hasil penelitian yang telah dilakukan maka dapat diambil sebuah kesimpulan mengenai desain model basisdata monitoring kesehatan anak usia dini dengan pedekatan holistic integrative adalah:

1) Penelitian ini telah menghasilkan 10 file yang saling berelasi antara yang satu dengan yang lain melalui model pemetaan derajat cardinality one-to-one, one-to-many/ many to one dan many 
to many hasil dari pemodelan Entity Relational (ER). 10 file yang terbentuk terdiri dari 6 file master dan 2 file transaksi serta 2 file antara.

2) Relasi antar file dapat dibuat setelah adanya konversi antar file melalui penempatan kunci utama (primary key) yang berubah menjadi kunci kedua (foreign key) pada file transaksi.

3) Model relational hasil konversi yang telah dilakukan merupakan hasil dari normalisasi sampai pada tahap ketiga. ( $\left.3^{\text {th }} \mathrm{NF}\right)$.

4) Rancangan basisdata ini dapat dijasikan sebagai acuan untuk implemantasi system dengan menggunakan aplikasi online system, yang bertujuan untuk memudahkan akses kepada user yang terlibat.

\subsection{SARAN}

1) Perancangan model basisdata dapat diimplementasikan menggunakan aplikasi online system sehingga memudahkan user melakukan monitoring kesehatan pada anak usia dini melalui aplikasi berbasis web/ mobile programming.

2) Kerjasama dengan Pemda Serang untuk dapat menerapkan basisdata monitoring kesehatan anak paud kedalam bentuk aplikasi on-line system berbasis holistic integrative sehingga memudahkan orangtua untuk memantau kesehatan dan keselamatan anaknya.

\section{Referensi}

[1.] Adharani, Y., \& Meilina, P. (2017). Penjadwalan Imunisasi Anak Usia 0 - 18 Tahun. Seminar Nasional TEKNOKA, 2(ISSN 2502-8782), 88-95.

[2.] Apriliana Kuntoro Astuti. (2016). Pelaksanaan Perilaku Sehat Pada Anak Usia Dini di paud Purwomukti Desa BAtur Kecamatan Getasan, 6, 264-272.

[3.] Dinas kesehatan. (2015). Profile Kesehatan Kota Serang. Dinas kesehatan Kota Serang.

[4.] DR. Sudibyo Alimoeso, M. (2013). Panduan Pelaksanaan Kegiatan Bina Keluarga Balita (BKB) Yang Terintegrasi Dalam Rangka Penyelenggaraan Pengembangan Anak Usia Dini Holistik Integratif. Indonesia: Badan Kependudukan dan Keluarga Berencana Nasional.

[5.] Kusnandi Rusmil. (2015a). Melengkapi/ Mengejar Imunisasi Bagian 1. Indonesia: Ikatan Dokter Anak Indonesia. Retrieved from http://www.idai.or.id/artikel/klinik/imunisasi/melengkapi-mengejar-imunisasi-bagian-i

[6.] Kusnandi Rusmil. (2015b). Melengkapi/ Mengejar Imunisasi Bagian 3. Indonesia: Ikatan Dokter Anak Indonesia. $\quad$ Retrieved from http://www.idai.or.id/artikel/klinik/imunisasi/melengkapi-mengejar-imunisasi-bagian-iii

[7.] Kusnandi Rusmil. (2015c). Melengkapi/ Mengejar Imunisasi Bagian 4. Indonesia: Ikatan Dokter Anak Indonesia. Retrieved from http://www.idai.or.id/artikel/klinik/imunisasi/melengkapi-mengejar-imunisasi-bagian-iv

[8.] Linawati Zulfa Indra Laila. (2013). Di, Penyelenggaraan Program Paud Holistik Integratif Semarang, Paud Siwi Kencana Kota, 2(1), 73-83. Retrieved from https://journal.unnes.ac.id/sju/index.php/jnfc

[9.] Nurus Sa'idah. (2017). Analisis Penggunaan Sistem Pendaftaran On-line (E-Health) Berdasarkan Unified Theory Of Acceptance And Use Of technology (UTAUT), 5, 72-81.

[10.] S, A. C. D., Zahraini, D. A., \& Sabarini, S. (2013). Desain Pengembangan Anak Usia Dini Holistik Non Formal (Penelitian Research and Development di Pos PAUD Mutiara Kelurahan Lamper Lor Kecamatan Semarang Selatan), 2(1), 105-126. https://doi.org/http://dx.doi.org/10.26877/paudia.v2i1\%20mei.365. 
